\title{
Entre bolhas e portas: um diálogo sobre a noção de intimidade entre Peter Sloterdijk e Gaston Bachelard
}

\section{Between bubbles and doors: a dialogue about the notion of intimacy between Peter Sloterdijk and Gaston Bachelard}

DOI: 10.12957/ek.2020.46739

\section{Dndo. Renan Silva Carletti}

carletti.rs@gmail.com

Universidade de São Paulo (USP)
Prof. Dr. Gilberto Safra

iamsafra@uol.com.br

Universidade de São Paulo (USP)

\section{RESUMO}

Este artigo pretende apresentar como a noção de "intimidade", apresentada pelo filósofo alemão Peter Sloterdijk em sua obra Esferas I - Bolhas, em diálogo com o mesmo tema abordado em A poética do espaço de Gaston Bachelard. Desenvolveremos, inicialmente, como a intimidade é compreendida por cada autor e sua articulação com as concepções de "exterioridade" e "espaço". Posteriormente, pela perspectiva do escritor Juliano Pessanha, assinalaremos a crítica à abordagem de Martin Heidegger que converge ambos autores e mostraremos consonâncias e divergências entre os mesmos. Por último, poderemos compreender como o "pensamento esferológico" do filósofo alemão guarda raízes nas reflexões sobre a imaginação e poesia do pensador francês.

\begin{abstract}
This article intends to present how the notion of "intimacy", presented by the German philosopher Peter Sloterdijk in his work "Spheres I - Bubbles", was developed in dialogue with the same theme addressed in Gaston Bachelard's "The Poetics of Space". Initially, we will develop how intimacy is understood by each author and its articulation with the conceptions of "exteriority" and "space". Later, from the perspective of writer Juliano Pessanha, we will point out the criticism of Martin Heidegger's approach that converges both authors and show consonances and divergences between them. Finally, we can understand how the "spherological thinking" of the German philosopher is rooted in the reflections on the imagination and poetry of the French thinker.
\end{abstract}

Palavras-chave: Sloterdijk. Bachelard. Esferologia. Intimidade. Exterioridade. Espaço.

Keywords: Sloterdijk. Bachelard. Spherology. Intimacy. Exteriority. Space. 


\section{Introdução}

O presente artigo pretende discutir o conceito de "intimidade" apresentado pelos filósofos Peter Sloterdijk e Gaston Bachelard. Sua construção ocorreu a partir da participação em cursos realizados no Instituto Dasein em São Paulo. Na ocasião os cursos que inspiraram tal publicação foram a formação teórica em psicologia fenomenológicahermêutica, "Estranho e o Íntimo" ministrado por Juliano Pessanha" e "Poética do Espaço" conduzido por Nichan Dichtchekenian.

Nos cursos, em especial, nos dois últimos, os professores apresentaram uma perspectiva crítica da abordagem construída por Heidegger (2012) em Ser e Tempo. Ambos amparados nos autores que sustentam este artigo (Peter Sloterdijk e Gaston Bachelard) descreveram a pouca discussão da noção de intimidade realizada por Martin Heidegger em sua obra principal. Trata-se não de uma forma de crítica desmesurada sobre o autor, mas sim, apontamentos sobre aspectos que ele se dedicou de forma menos intensa.

Portanto, temos como proposta não apresentar os principais conceitos da obra Ser e Tempo de Martin Heidegger (2012) que dialogam com a noção de intimidade, mas sim, os tensionamentos realizados pelos autores e seus leitores contemporâneos. Entendemos que a leitura realizada pode não ser compartilhada em unanimidade por seus estudiosos, tratando-se de um autor plural em suas interpretações e possibilidades de caminhos construídos a partir delas. Entretanto, salientamos que a temática da intimidade a partir de sua proposta fenomenológica, foi pouco abordada, tornando pertinente a exploração aqui realizada.

Deste modo, o artigo apresentará o conceito de intimidade a partir dos filósofos Peter Sloterdijk e Gaston Bachelard. Ambos foram influenciados pela obra de Martin Heidegger, entretanto buscaram novas perspectivas sobre temas que o autor de Ser $e$ Tempo se dedicou. Iniciaremos o percurso com a noção de intimidade a partir da obra Esferas I de Peter Sloterdijk e, na sequência, descreveremos o mesmo tema sob a ótica de Gaston Bachelard em A poética do espaço. Por último, buscaremos descrever aproximações e distanciamentos entre as compreensões de ambos autores. 


\section{Intimidade em Esferas I de Peter Sloterdijk}

Peter Sloterdijk (1947-) estudou Filosofia e História Germânica nas Universidades de Munique e Hamburgo e, atualmente, ocupa o cargo de reitor da Escola Superior de Design, em Karlsruhe na Alemanha. Considerado um autor da segunda geração da Escola de Frankfurt (ROCCA, 2008a), o que o difere enquanto pensador não é sua formação, mas sua propensão a reunir diversos campos de saberes.

Antropologia, literatura, psicanálise, arquitetura, mesmerismo1, teologia, experiências místicas, arqueologia, história da arte, mitologia. Estas são apenas algumas das áreas que Sloterdijk é capaz de colocar em diálogo e profusão para que novos conceitos sejam formados a partir do olhar para este caleidoscópio de produções culturais humanas (ROCCA, 2008a). Sua primeira obra de destaque nomeada Crítica da Razão Cínica (2012), publicada originalmente em 1983 na Alemanha (na ocasião do bicentenário da Crítica da Razão Pura de Immanuel Kant), expõe a irreverência do autor que busca reavaliar a posição da filosofia na contemporaneidade.

Posteriormente a este livro, o ensaio filosófico "Estranhamento do Mundo", publicado em 1993, pode ser considerado como um preâmbulo para sua obra magna, a trilogia "Esferas". No ensaio, Sloterdijk (2008) busca realizar uma reflexão de inspiração heideggeriana sobre a presença do humano no mundo. No capítulo inicial, o filósofo relaciona o perceber-se humano com os chamados "blocos erráticos2", em que o espanto com o próprio "eu" no mundo seria como estes blocos que "estão ai". Diante disto, abrese a possibilidade da consciência fazer-se com o mundo. O reconhecimento desta condição de estar jogado aleatoriamente no mundo não se dá de forma tranquila, mas por meio do "inesperado, o rebelde e o inquietante que o extático achamento pessoal pode ser" (SLOTERDIJK, 2008, p. 16); esta surpresa já foi devidamente expressa pela palavra "existência". No entanto, o termo passou a ser corriqueiro e perdeu sua força de mostrar o inédito do existir humano (SLOTERDIJK, 2008).

\footnotetext{
1 Prática proposta pelo médico-físico Franz A. Mesmer em que se utilizava do magnetismo de animais e plantas para o tratamento e cura de paciente, no final do século XVIII na França. Sloterdijk irá argumentar que Mesmer foi pioneiro na discussão da importância da relação entre médico e paciente, o que mais tarde, Freud denominou "transferência" (SLOTERDIJK, 2003).

2 Formações geológicas que foram transportadas durante a última era glacial e encontram-se espalhadas em diversas partes do mundo (SLOTERDIJK, 2008).
} 
Sloterdijk desnuda a indeterminação humana nesta obra por meio de afirmações como "O que chamamos homem é, na verdade, o ser vivo aporético sem saída. Ele é o ser que tem de fazer de si mesmo algo diferente do que é, para poder suportar sua falta de saída" (SLOTERDIJK, 2008, p. 35). O filósofo grifa o caráter desesperador que a existência aparece ao humano, já que ele se vê na emergência de buscar um modo diferente de ser por não ter as bases que sustentam em sentido e origem sua presença no mundo.

Na sequência de sua bibliografia surge o projeto Esferas3, o qual em seu âmbito geral é interpretado por Rocca (2008a) como uma trilogia que caminha na trilha de obras que buscam um apanhando geral sobre a história humana e, por isso, segue a influência da maioria dos autores alemães com uma vocação para a reflexão sobre a totalidade da experiência humana. O primeiro volume, o qual pretendo me focar, pode ser considerado, como dito pelo próprio autor, uma elaboração do conceito de intimidade (SLOTERDIJK \& HEINRICHS, 2007). Tendo o ponto de partida na dupla mãe-bebê, o filósofo ressalta o processo de "esferização" que acontece a cada instante e possibilita o existir de cada sujeito (SLOTERDIJK \& HEINRICHS, 2007). Sloterdijk revela seu estilo utilizando linguagem pouco convencional com termos que misturam poesia, filosofia e expressões que lembram os antigos alquimistas, como vemos no trecho a seguir:

\footnotetext{
Não se convence todo bebê que não se é vítima do desamparo e da vantagem de ter nascido, se não porque há mamilos eudaimônicos4, espíritos-caramelo benignos, ampolinhas conjuradas, fadas bebíveis que velam discretamente em sua cama para irromper de vez em quando tranquilizadoramente em seu interior? (SLOTERDIJK, 2003, p. 96-97, tradução nossa)
}

Sem poupar recursos poéticos, Sloterdijk afirma que o bebê é retirado do desamparo por experiências de intimidade. Este modo de escrita de Sloterdijk não se trata apenas de recurso estilístico, mas uma alteração precisa na forma de descrever e analisa certos fenômenos para viabilizar seu projeto de dissolução do enfoque substancialista. Para ele há um modo de dizer que se situa entre a linguagem científica e a linguagem poética que ainda não foi devidamente explorado (SLOTERDIJK, 2003).

\footnotetext{
${ }_{3} \mathrm{O}$ projeto é composto pela trilogia: I - Globos, II - Globos e III - Espumas

4 Sloterdijk foge dos termos heideggerianos para apresentar uma linguagem que se enviesa pela literatura e poesia. Ao invés dos dizeres assépticos do "ser-ai", "ser-em" e "ser-com", Sloterdijk vale-se de metáforas e comparações para dizer sobre a existência humana. Neste caso, daimon trata-se de um termo utilizado por Sócrates para referir-se a algo de divino que o humano é capaz de possuir (PLATAO apud MORAIS, 2010)
} 
Para pensar as relações íntimas em Sloterdijk deve-se, inicialmente, partir de uma crítica da substância. $\mathrm{O}$ autor quer propor uma nova forma de dizer sobre as relações e para isso necessita enfatizar o modo tradicional de pensarmos a intimidade como interioridade desconexa das relações que estabelecemos. O livro Esferas I, também denominado como uma "arqueologia do íntimo" (SLOTERDIJK \& HEINRICHS, 2007, p. 113), busca responder a seguinte pergunta:

Como devemos falar destas relações pouco visíveis entre pares se quisermos descrevê-las corretamente, isto é, não como um funcionário de registro civil ou terapeuta conjugal, não como um voyeur ou um leitor de romances, mas com radicalidade filosófica e atenção morfológica? (SLOTERDIJK \& HEINRICHS, 2007, p. 121)

Para isso, Esferas I se inicia com a imagem de um garoto soprando bolhas de sabão, seguido de uma longa descrição desta cena e de um esboço do em que ele proclama como o início da "ontologia com o número Dois" (SLOTERDIJK \& HEINRICHS, 2007, p. 121). O ar que sai dos pulmões do garoto e infla a bolha que se desprende de seu brinquedo é a síntese da constituição humana para Sloterdijk. O "existir", primordialmente, não tem a ver com "pensamento" ou "consciência", mas com a capacidade de se emergir em um outro para que se possa imergir para o mundo.

Estamos desde o útero: juntos. Juntos com um outro corpo e nutridos por um outro: a placenta. Denominado de "órgão rejeitado" (SLOTERDIJK, 2003), este acompanhante perdeu seu lugar na sociedade atual. Descartado como lixo, o “acompanhante originário" (SLOTERDIJK, 2003) em outras épocas, era um outro que deveria ser metamorfoseado em comida ou ritualizado como agradecimento por sua copresença. No entanto, na época do corpo-máquina, ele é apenas um dejeto, uma máquina não precisa de acompanhante, necessita apenas de combustível, nutrientes, suplementos, vitaminas e uma "gorda saúde" (DELEUZE, 2006).

Neste sentido, constituir-se não tem a ver com tornar-se um, mas originar-se de uma relação. É o estar com o outro que vai condicionar a presença no mundo. Este "estar com" não nos leva a perguntas sobre as substâncias que constituem estes seres das relações, mas sobretudo a respeito do espaço gerado por esta dupla. Com isso, Sloterdijk quer derrubar todo arcabouço teórico construído sobre a noção de "indivíduo" derivada da tradição de um pensamento voltado para a substância. 
Para estremecer estas estruturas do pensamento do "Um", Sloterdijk propõe temas pouco explorados na filosofia e apresenta um vocabulário pouco usual para filósofos. Algumas expressões centrais para ele são: “a relação, a conexão, a flutuação num dentrode-algo e num com-algo, o estar contido num entre" (SLOTERDIJK, 2002, pg. 115). Deste modo, indivíduos e substâncias deixam de ser personagens centrais na constituição humana e passam a ser coadjuvantes num processo constante de flutuação entre polos que estão em relação. A perspectiva da intimidade, deixa em segundo plano, estes conceitos que, para Sloterdijk, até o momento foram majoritários na tradição filosófica. Deste modo, a intimidade não são dois indivíduos em uma relação, mas uma forma de descrever que busca enfatizar esse espaço que é troca, fluxo e conexão.

\section{A dialética exterior-interior em Gaston Bachelard}

A obra Poética do Espaço, de Gaston Bachelard (1993), busca compreender a condição humana por meio de imagens poéticas. Colocando-se como um fenomenólogo da imaginação, Bachelard compreende que os poetas são porta vozes das facetas primordiais do existir humano. Vale-se de diversas imagens poéticas como miniatura, imensidão, ninho, conchas, cantos e entre outros, que desenham sua fenomenologia dos espaços. Para o autor, a intimidade está associada a uma imensidão íntima que se distingue em consonância com a vastidão da exterioridade. $\mathrm{O}$ desabrochar desta intimidade ocorre no espaço da casa que como escultor adorna e entalha os aspectos íntimos do humano (BACHELARD, 1993).

Neste artigo pretendemos nos deter sobre dois capítulos que tratam da tríade intimidade-exterioridade-espaço. Os capítulos “A imensidão íntima” e "A dialética do exterior e do interior" evidenciam o diálogo com "Esferas I - Bolhas” de Peter Sloterdijk. No capítulo "A imensidão íntima", Bachelard (1993) expõe as imagens do "imenso" e do "vasto" como termos que sintetizam aspectos da experiência humana. Ambas congregam as seguintes imagens opostas, sintetizadas por meio dos escritos dos poetas: “o espetáculo exterior [que] bem ajuda a revelar uma grandeza íntima" (p. 197). Já neste trecho, o autor começa a nos dar pistas de como trabalha a articulação das noções de exterior e íntimo. Ambos não existem como antônimos, mas articulam-se e se correspondem constantemente. Tal conjunção é feita sob a noção de espaço, a qual pode ser expressa 
com precisão pelas palavras de Rainer Maria Rilke a respeito da contemplação de uma árvore:

\author{
O espaço, fora de nós, ganha e traduz as coisas; \\ Se quiseres conquistar a existência de uma árvore, \\ Reveste-a de espaço interno, esse espaço \\ Que tem seu ser em ti. Cerca-a de coações. \\ Ela não tem limite, e só se torna realmente uma árvore \\ Quando se ordena no seio de tua renúncias
}

Em sua descrição, Rilke explicita que o espaço é o palco onde interior e exterior dialogam conjurando a experiência humana no mundo. E tal como já exposto por Bachelard, o trecho: "Ela não tem limite" reforça o caráter do "imenso" presente tanto na compreensão do exterior como do interior. Entretanto, é na limitação destas noções que a experiência se faz como indicado na expressão: "Cerca-a de coações".

Assim, conclui o autor neste trecho: "Os dois espaços, o espaço íntimo e o espaço exterior, vêm constantemente estimular um ao outro em seu crescimento" (BACHELARD, 1993, p. 205). Bachelard pretende com tal citação romper com a concepção de que a afetividade pertence ao “espaço íntimo”. Para ele, a expressão poética da afetividade liberta-a para o exterior, expandindo-a e quebrando qualquer cerceamento interior. Tal libertação, também chamada de "elaboração" por psicanalistas, pode ser compreendida no trecho do poema de Superville:

Conheço uma tristeza com cheiro de abacaxi Sou menos triste, sou mais docemente triste6

O cheiro do abacaxi expande a tristeza e a adoça. Articula e unifica a interioridade e a exterioridade no espaço único da experiência. Mais uma vez, Rilke sintetiza com exatidão: "Por todos os seres se desdobra o espaço único, espaço íntimo no mundo..." (RILKE apud BACHELARD, 1993, p. 206). Portanto, a dupla interior-exterior é compreendida como consonante (BACHELARD, 1993) exprimindo a própria imensidão da experiência humana.

Bachelard detalha a posição do humano diante do exterior e o interior no capítulo seguinte denominado "A dialética do exterior e do interior". De início, critica a naturalidade com que tratamos esta díade como se referisse a opostos como sim ou não.

5 RILKE apud BACHELARD, 1993, p. 204.

6 SUPERVILLE apud BACHELARD, 1993, p. 206. 
Refere-se a um "primeiro mito do exterior e do interior" (HYPPOLITE apud BACHELARD, 1993, p. 216), como forma alienante de pensar a dinâmica da experiência, a qual toma proporções incalculáveis que nos impede de propor outros modos de compreensão. Outras díades se desdobraram desta dupla como o aquém-além e aqui-aí, advérbios que reduziram as possibilidades de compreender uma fenomenologia do espaço.

Para confundir esta oposição, Bachelard convoca o poeta Jean Tardieu:

Para avançar eu me volto sobre mim mesmo

Ciclone pelo imóvel habitado7

Bachelard, inspirado em Tardieu, propõe, ao invés da díade tradicional, pensar o humano como um ser espiralado e desfixado. Ou seja, aquele que se designa dotado de um centro bem definido, mas que jamais poderá atingi-lo. "Toda expressão o desfixa" (BACHELARD, 1993, p. 218). A ilusão de fixar-se em qualquer terreno interior é tensionada por qualquer expressão dispersada na vastidão do mundo.

Esta alteração leva o fenomenólogo dos espaços e da imaginação a uma nova proposição: "Precisamente, a fenomenologia da imaginação poética permite-nos explorar o ser do homem como o ser de uma superfície, da superfície que separa a região do mesmo e a região do outro" (BACHELARD, 1993, p. 224). Como alternativa a esta proposição do ser espiralado, Bachelard levanta uma nova forma espacial de compreensão do humano: coloca-o como um ser de superfície. Com esta proposta, quer romper de vez com a oposição interior-exterior e propor uma "zona de superfície sensibilizada" (p. 224).

Por último, Bachelard propõe ainda uma última imagem: "O homem é o ser entreaberto" (BACHELARD, 1993, p. 225). Com esta expressão, quer ressaltar o luscofusco em que ocorre a presença humana, compreendendo-a como aquela que quer se manifestar ao mesmo tempo em que busca se ofuscar. Remetendo o humano à porta, Bachelard quer, por fim, propor o humano como ser medial que ora tenta se fechar completamente, ora se manter totalmente aberto. Entretanto, fracassa nestas tentativas radicais de esconder frestas ou ignorar fechaduras.

7 TARDIEU apud BACHELARD, 1993, p. 218. 


\title{
4. Entre portas e bolhas: diálogos entre Bachelard e Sloterdijk
}

Ao realizar o diálogo entre os dois autores partiremos dos escritos de Juliano Pessanha (2016) para sustentar esta aproximação. Cabe ressaltar que trataremos "estranhamento" e "exterioridade" como expressões que correspondem ao mesmo fenômeno, já que os dois termos ressaltam o caráter contingencial da existência humana, bem como seu caráter de "jogado no mundo". Ainda que estes termos guardem raízes na filosofia de Martin Heidegger (2012), nossa discussão será feita a partir da interpretação realizada por Juliano Pessanha (2016), pois como apresentado na introdução deste artigo, partimos de um curso conduzido por ele para apresentar esta discussão.

Como apontado por Pessanha (2016), o projeto "Esferas" é "uma história cujo protagonista é o espaço" (p. 100, grifo nosso). Sloterdijk recolhe na Poética do Espaço de Gaston Bachelard a epígrafe do primeiro volume: "A dificuldade que havíamos de superar... consistia em nos mantermos longe de qualquer evidência geométrica. Dito de outro modo, devíamos partir de uma espécie de intimidade do redondo" (apud SLOTERDIJK, 2003, p. 19, tradução nossa). Com esta citação, Sloterdijk nos mostra quem o incentivou a um pensamento "esferológico", propondo um modo de reflexão que se afastasse de ângulos retos ou obtusos, que fugisse de arestas bem delimitadas, escapando das luzes iluministas que passaram a produzir cegueira por não nos permitir enxergar nada além das evidências geométricas. $\mathrm{O}$ redondo é o espaço que possibilita o acolhimento do humano e o entrega a possibilidade de proteção e de imunologia diante das contingências da experiência. Nas palavras de Pessanha (2016), ao comentar Sloterdijk:

\begin{abstract}
A orfandade requer a sustentação, assim como o ser ejetado e jogado no mundo pede um receptáculo imunológico de proteção e hospitalidade. O ser humano precisa ser dois dentro de um receptáculo imunológico para tornar-se um depois. Se ele não participa desse dueto ressonante em um espaço interior, não emerge como um si mesmo. O espaço interior sustentado é a província onde acontece o belo salto em que crio e sou criado por aquilo que encontro (p. 107).
\end{abstract}

Esta ideia, apresentada pelo escritor brasileiro, de receptáculo imunológico é presente em toda trilogia. Sloterdijk compreende que saltamos de espaços em espaços que nos garantem uma proteção mínima e que as construções histórico-sociais nos encaminham para isto. Do útero para a mãe, desta para a família, depois para a sociedade, 
desta para a religião e/ou a política... Espaços imunológicos que originariamente nos remetem ao regaço da casa, como mostrado por Bachelard:

\begin{abstract}
Antes de ser "jogado no mundo", como o professam as metafísicas apressadas, o homem é colocado no berço da casa. E sempre, nos nossos devaneios, ela é um grande berço. Uma metafísica concreta não pode deixar de lado esse fato, esse simples fato, na medida em que ele é um valor, um grande valor ao qual voltamos nos nossos devaneios. O ser é imediatamente um valor. A vida começa bem, começa fechada, protegida, agasalhada no regaço da casa (BACHELARD, 1993, p. 26)
\end{abstract}

A casa para Bachelard não é o espaço da "família burguesa", mas aquele que garante a possibilidade de acolhimento do modo particular de cada ser, desenhando assim sua intimidade. Ressaltamos desta citação o que também está claramente presente nas reflexões de Sloterdijk: a afirmação de que não há como habitar o mundo se antes não houver a experiência íntima como ponto de partida. Ou seja, é necessário primeiro habitar dentro de um outro que sustente um asseguramento mínimo diante da experiência mundana.

Aqui há uma divergência, pois o primeiro receptáculo para Sloterdijk é o útero, a própria mãe; a casa seria posterior a proteção experimentada no período gestativo. No entanto, se mantém o aspecto relacional que Sloterdijk atribui ao espaço tal como Bachelard. Diferente da proposta kantiana em que o espaço é o primordial no existir humano, Sloterdijk subordina-o à relação (WAMBACQ e VAN TUINEN, 2017). Ou seja, não se pode pensar o espaço fora do contexto relacional. Por exemplo, a relação mãe-bebê sustenta uma perspectiva espacial:

Tudo o que acabei por escrever a este respeito parte da compreensão de que a mãe, logo de início, não deve ser pensada como uma pessoa, mas como um lugar, uma forma-receptáculo, uma estrutura imunitária espacial, e com um espaço de ressonância, uma voz (SLOTERDIJK \& HEINRICHS, 2007, p.136).

Sloterdijk almeja estabelecer um conjunto de "paradigmas da simbiose" (SLOTERDIJK \& HEINRICHS, 2007, p. 133). Isto quer dizer que não é só a relação mãe-bebê que experimenta uma díade de animação dupla, mas também é o que ocorre na amizade, relação terapêutica, casais enamorados, entre outros possíveis. Todas estas díades são polos que se nutrem um do outro. A extensão deste paradigma fíca nítida no 
prefácio de Esferas I quando Sloterdijk faz referência ao conceito de transferência freudiano e afirma que se mantenha afastado de sua obra quem não estiver disposto a um “elogio à transferência e refutação a solidão" (SLOTERDIJK, 2003, p. 24, tradução nossa).

Em suas reflexões, Bachelard é menos afeito a tecer paradigmas e perspectivas do desenvolvimento humano. O fenomenólogo francês está mais atento as imagens poéticas e como elas podem fornecer elementos para compreensão da intimidade enquanto modo de se apropriar do mundo. Vejamos que, diferente de Sloterdijk, ele não está preocupado em como esta expressa-se no bebê, nos casais, nas amizades ou na relação terapêutica. Em Bachelard, a intimidade é um fenômeno do existir humano o qual a poesia anuncia quando diz do lugar que lhe é próprio, o lugar da enunciação de um dizer inaugurador.

Apesar desta divergência, a dinâmica estranho e íntimo, aproxima intensamente os dois autores. No quarto excurso de Esferas I, denominado "No ser-aí há uma tendência essencial ao acompanhamento - A doutrina do lugar existencial em Heidegger", o filósofo retoma trechos da obra Ser e Tempo de Martin Heidegger (2012) e argumenta que o tema do "ser-com" foi pouco ou quase nada explorado por seu antecessor. "Ser-com", para Sloterdijk, significa poder explorar a condição originária do humano em estar acompanhado (SLOTERDIJK, 2003). Portanto, "O par seria, portanto a forma esférica primária que temos de levar em conta. A constituição diádica é a situação das situações" (SLOTERDIJK \& HEINRICHS, 2007, p. 121).

Para Sloterdijk, Heidegger tratava do humano sem descrevê-lo nestas experiências primeiras de intimidade e que deveria colocar-se diante da angústia para recuperação de seu estado de indeterminação (ser-ai), seu posicionamento era radical diante da possibilidade de ser tratado como ente na relação com o outro (ser-com). Ou seja, para Heidegger, ser-com é entregar seu caráter originário de indeterminação para um contato massificador e nivelador diante do outro (HEIDEGGER apud SLOTERDIJK, 2003). Enquanto Sloterdijk (2003) dedica-se à descrição e dignificação destas experiências como constituição de possibilidades de habitar o mundo.

Desta forma, entendemos que tanto Sloterdijk (2003) como Bachelard oferecem um contraponto à postura heideggeriana. Tal como o primeiro, Bachelard critica Heidegger em alguns momentos de sua obra: 
De nosso ponto de vista, do ponto de vista de um fenomenólogo que vive das origens, a metafísica consciente que se situa no momento em que o ser é “jogado no mundo" é uma metafísica de segunda posição. Ela passa por cima de preliminares em que o ser é o bem-estar, em que o ser humano é colocado num bem-estar, no bem-estar associado primitivamente ao ser (BACHELARD, 1993, p. 27).

Há nos autores tratados neste artigo uma preocupação em atribuir papel central aos momentos fundadores da experiência no mundo. Para Sloterdijk (2003), o útero é o espaço de proteção primeira onde o bem-estar é pleno, já para Bachelard (1993), a casa é o paradigma da proteção e bem-estar. Portanto, ambos se posicionam como críticos da postura heideggeriana de abordar o humano com pouco destaque para as experiências de intimidade.

Por último, apresentaremos como o caráter "medial" do humano é abordado no pensamento de cada autor. Sloterdijk apresenta uma síntese da dinâmica interior-exterior em um trecho de "O Sol e A Morte":

[...] onde está o homem? Esta resposta, a meu ver, não depende da psicologia mas da teoria do espaço: numa primeira fase, os seres humanos estão inseridos numa esfera bipolar, num espaço relacional de tonalidade íntima que só pode existir devido à vinculação e à adesão do que vivem em comum, um espaço de proximidade de que mal nos apercebemos de tal forma lhe pertencemos e cuja ausência lastimamos quando verificamos tê-lo perdido. Para que as esferas como tais chamem a atenção, é preciso que rebentem. Só quando as damos por perdidas é que elas podem converter-se em objeto teórico. Estas relações de proximidade são recipientes autógenos, uma expressão estranha correspondente a um facto não menos estranho, dado que se alude a uma situação em que o conteúdo se contém a si mesmo (SLOTERDIJK \& HEINRICHS, 2007, p. 119).

Sloterdijk apresenta esta resposta após comentar a resposta freudiana à pergunta sobre “o lugar do homem”. Para ele, Freud (1923/2011) responde a esta questão com a formulação da segunda tópica em que o homem se situa a partir de lugares intrapsíquicos (id, ego e superego). Contrapondo-se a esta perspectiva, Sloterdijk enxerga em Freud a reprodução da metafísica do indivíduo embebida de um maquinário psíquico-topológico. Ou seja, o espaço interior é privilegiado em detrimento do exterior. Diferente desta postura, Sloterdijk busca abordar o "espaço circundante", o qual gera proteção, possibilita o cultivo e florescimento da intimidade.

Entretanto, não se deve compreender esta intimidade como uma interioridade exclusiva e privativa desconexa do espaço circundante. Sloterdijk explicita que o humano 
é gerado e, ao mesmo tempo, gerador destes espaços de proteção. Assim, devemos compreender a intimidade, para o pensador alemão, não como uma interioridade escavada e profunda, mas como polo de experiência. A experiência humana flutua entre polos e esferas, como afirma o próprio Sloterdijk: "Por isso digo que não existem indivíduos, mas unicamente divíduos; os homens só existem como partículas ou polos de esferas" (SLOTERDIJK \& HEINRICHS, 2007, p. 119).

Aqui, o diálogo entre bolhas e portas fica nítido. Se para Sloterdijk o humano vive polos de esferas compartilhadas, para Bachelard, uma noção muito próxima se traduz com a imagem da porta que nunca está completamente aberta ou fechada, mas sempre entreaberta. Contudo, a dinâmica interior-exterior em Sloterdijk parece ainda ser mantida quando ele afirma que as esferas necessitam explodir para que então tornem-se objetos teóricos. A abertura para o exterior parece vir posterior ao processo de intimidade com o outro. Ainda que a noção de "espaço circundante" proponha uma ruptura desta dicotomia, ela permanece menos nítida do que na proposta do pensador francês. Para Bachelard, por meio da noção de "zona de superfície sensibilizada" citada anteriormente, os espaços de interioridade e exterioridade parecem ocorrer de forma simultânea e recíproca.

Cabe por fim ressaltar que as reflexões de Sloterdijk em Esferas I - Bolhas são pautadas em relações entre humanos, enquanto na Poética do Espaço de Bachelard predomina aproximações com objetos e a natureza. Entendemos que tal distinção ocorre devido ao tema que cada autor privilegiou em seus trabalhos, mas que ambos possuem fortes consonâncias ao tratar da noção de intimidade.

\section{Conclusão}

Compreendemos que os diálogos entre Bachelard e Sloterdijk não se reduzem ao exposto neste artigo. Outros temas como a "fenomenologia do redondo", capítulo da "Poética dos Espaços" de Bachelard e sua interlocução com a trilogia "Esferas" de Sloterdijk deve servir como inspiração para futuros estudos.

Sloterdijk (2003) nos apresenta uma microesferologia dos espaços buscando compreender a intimidade e sua constituição. Ao partir da descrição do espaço uterino, o autor busca fundamentar que a experiência íntima se mostra desde o início presente na constituição humana. Ao migrar para as descrições das relações entre um bebê o momento 
da amamentação, o autor dá continuidade ao âmbito relacional presente no tornar-se humano.

Bachelard (1993) que compõe a epígrafe do primeiro volume do projeto Esferas de Peter Sloterdijk, busca não estabelecer um caminho cronológico da intimidade como o faz o autor alemão. Ao invés deste percurso, o filósofo francês percorre o caminho das imagens, objetos e poesias para descrever uma experiência íntima que se estende para além do constituir-se humano. Para ele, há uma experiência íntima com a totalidade do mundo e não apenas com outro ser humano.

Partindo da perspectiva de Pessanha (2016), assinalamos como a noção de intimidade tanto em Sloterdijk como em Bachelard vai de encontro à filosofia heideggeriana. No olhar do escritor brasileiro, Heidegger é um interlocutor do estranho que busca resguardar o humano de qualquer possibilidade de determinação, levando-o a um lugar de estrangeiro do próprio mundo, enquanto Sloterdijk e Bachelard expõem a necessidade de intimidade com o outro e com o mundo como experiências intrinsecamente humanas e necessárias para se poder estar no mundo.

Entretanto, ressaltamos que ambos os autores guardam também em seus pensamentos aspectos que contemplam um olhar da exterioridade, não sendo exclusivamente pensadores do íntimo. Na conjunção destes modos de relação com o mundo, encontramos modos humanos, demasiadamente humanos.

\section{Referências bibliográficas}

BACHELARD, Gaston. A poética do espaço. Trad. Antônio de Pádua Danesi. São Paulo: Martins Fontes, 1993.

DELEUZE, Gilles. Crítica e Clínica. Trad. Peter Pál Pelbart. SP: Editora 34, 2006.

FREUD, Sigmund. Obras Completas Vol. 16 - "O Eu e o id”, "Autobiografia” e outros textos. Trad. Paulo César de Souza. São Paulo: Companhia das Letras, 1923/2011.

HEIDEGGER, Martin. Ser e Tempo. Trad. Fausto Castilho. Campinas: Editora Unicamp / Rio de Janeiro: Vozes, 2012. 
PESSANHA, Juliano Garcia. Apresentação heterodoxa de um ponto cego de Heidegger visto por Sloterdijk, In: MORATO, H. T. P. \& EVANGELISTA, P. E. R. A. Fenomenologia Existencial \& Prática em Psicologia, Rio de Janeiro: Via Verita, 2016. MORAIS, Emilia Maria Mendonça de. A natureza do filósofo. Kriterion, Belo Horizonte: v. $51, \quad$ n. $122, \quad$ p. 473-488, 2010. Disponível em $<\mathrm{http} / / / \mathrm{www}$.scielo.br/scielo.php?script=sci_arttext\&pid=S0100-

512X2010000200009\&lng=en\&nrm=iso> acessado em 23 Aug. 2018. http://dx.doi.org/10.1590/S0100-512X2010000200009.

ROCCA, Adolfo Vásquez. Peter Sloterdijk; esferas, helada cósmica y políticas de climatización. Valência: Edicions Alfons el Magnànim, 2008.

SAFRANSKI, Rüdiger. "Prólogo". In: SLOTERDIJK, P. Esferas I - Burbujas, Trad. Isidoro Reguera. Madrid: Siruela, 2003.

SLOTERDIJK, Peter. Crítica da Razão Cínica. Trad. Marco Casanova e outros. São Paulo: Estação Liberdade, 2012. Esferas I-Burbujas. Trad. Isidoro Reguera. Madrid: Siruela, 2003. O Estranhamento do Mundo. Trad Ana Nolasco. Lisboa: Relógio d’Água, 2008. SLOTERDIJK, Peter \& HEINRICHS, Hans-Jürgen. O Sol e a Morte. Trad. Carlos Correia Monteiro de Oliveira. Lisboa: Relógio d'Água, 2007.

WAMBACQ, Judith \& VAN TUINEN, Sjoerd. "Interiority in Sloterdijk and Deleuze". Palgrave Communications 3, Article number: 17072 (2017). Disponível em: https://www.nature.com/articles/palcomms201772 acesso em 29 ago. de 2017.

Recebido em: 24/12/2019 | Aprovado em: 13/04/2020 